Revista Colombiana de Entomología 2021, 47 (2): e11574• https://doi.org/10.25100/socolen.v47i2.11574

Revista Colombiana de Entomología 2021, 47 (2): e11574• Anderson Arenas, et al.

Book review/Reseña

\title{
Taxonomic revision of the Neotropical tiger beetle genera of the subtribe Odontocheilina (Coleoptera: Cicindelidae)
}

Revisión taxonómica de los géneros de escarabajos tigre neotropicales de la subtribu Odontocheilina (Coleoptera: Cicindelidae)

iD ANDERSON ARENAS-CLAVIJO ${ }^{1}$; (iD JAMES MONTOYA-LERMA ${ }^{1 *}$;

${ }^{1}$ Universidad del Valle, Ciudad Universitaria Meléndez, Calle 13 \# 100-00, Cali, Colombia. james.montoya@ correounivalle.edu.co

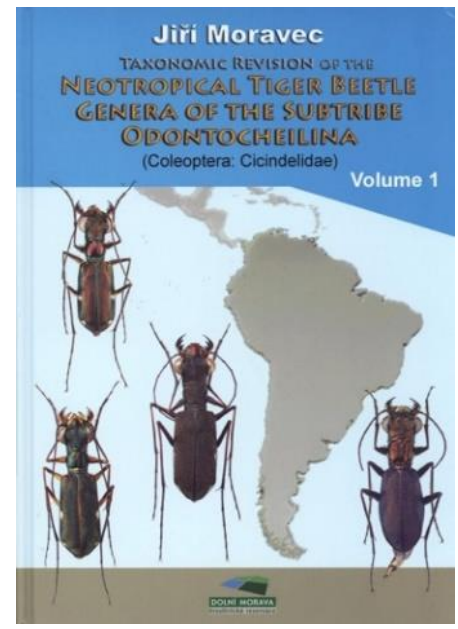

By Jiri Moravec

ISBN (volume 1): 978-80-270-5230-1 (2018)

ISBN (volume 2): 978-80-907849-0-1 (2020) Published: Biosfericka rezervace Dolni Morava, o.p.s.

\section{*Corresponding author}

James Montoya-Lerma, Ciudad Universitaria Meléndez, Calle 13 \# 100-00, Cali, Colombia; james.montoya@correounivalle.edu.co

Submitted: jul-31-2021

Published: sep-02-2021

Revista Colombiana de Entomología ISSN (Print): 0120-0488

ISSN (On Line): 2665-4385

https://revistacolombianaentomologia.univalle.edu.co

Open access

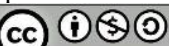

Publishers: Sociedad Colombiana de Entomología SOCOLEN (Bogotá, D. C., Colombia) https://www.socolen.org.co/ Universidad del Valle (Cali, Colombia) https://www.univalle.edu.co/

(C) 2021 Sociedad Colombiana de Entomología SOCOLEN y Universidad del Valle - Univalle
Beetles hold a certain charm for researchers, to the extent that Haldane ventured to consider them unusual in the Creation. Of these insects, the tiger beetles or cicindelids are particularly attractive, although, worldwide, they have certain taxonomic gaps. "Taxonomic revision of the Neotropical tiger beetle genera of the subtribe Odontocheilina (Coleoptera: Cicindelidae)" is a monumental work that largely fills these gaps and provides, without any doubt, a detailed revision of the taxonomy of 15 of the genera in this family.

The complete work offers a level of detail that is impressive, both for the number of morphological characteristics available for consultation, and for the high definition of the images (not few) that accompany the descriptions and redescriptions. It also provides keys for the identification of species and groups of species, both for females and males.

In the first volume (623 pages) the author deals with the genera Odontocheila, Cenothyla and Phyllodroma, and in the second volume (589 pages) he deals with the remaining genera (Mesochila, Beckerium, Ronhuberia, Brzoskaicheila, Poecilochila, Mesacanthina, Pentacomia, Cheilonycha, Eulampra, Pometon, Oxygonia and Opisthencentrus).

The structure of the treatment of each species contains: taxonomic history, repositories of type material, additional revised material (if any), label information, a differential diagnosis and respective variability, re-descriptions (when needed), and some data on biology and distribution. All this is complemented by a comments section where the author makes observations and important tips related to taxonomic work, such as the arrangement of labels, the movement of specimens between collections and potential errors incurred in previous descriptions (misidentifications, spelling, processing of specimens, etc.).

Worldwide, tiger beetles are very popular because of their ecological importance and their use as bioindicators in different environmental and agricultural contexts. Unfortunately, for some regions, the taxonomic resolution of the family Cicindelidae is still weak. This is the situation of Colombia, a megadiverse country where only 100 species of tiger beetle have been recorded. Thus, an update of the current taxonomic and faunistic knowledge, as a starting point for future systematic studies was greatly needed. Consequently, this book is undoubtedly a key reference for those who require reliable taxonomic resolution in their academic contributions to the group. The work is clearly the product of the extensive and particular dedication of Jiri Moravec (Czech Republic) to this family of insects. 